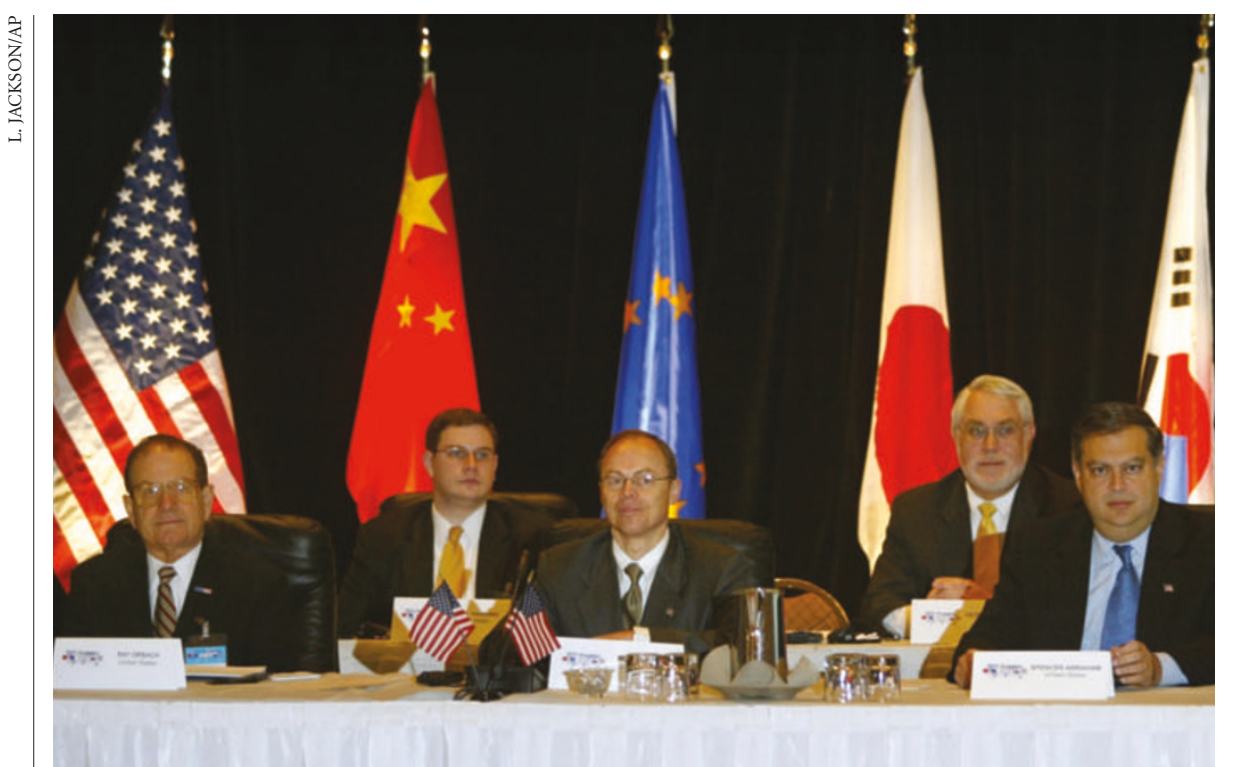

The US delegation at December's meeting, where stalemate set in over where to build ITER.

\title{
Partners fail to find common ground for fusion project
}

\section{Declan Butler, Paris}

Iter means 'the way' in Latin - but 'lost its way' might be a more apt description of the international fusion project that bears the name.

A technical assessment intended to break a stalemate over where to site the facility has itself ended in deadlock, with the six partners blaming each other for the lack of progress.

Negotiations over ITER's site have been stalled since a ministerial meeting in Washington last December, when the United States and South Korea backed the Japanese site at Rokkasho, and China and Russia supported the European Union's site at Cadarache in France. The US\$5-billion project seeks to show that heating plasma in a magnetic field can produce fusion energy.

But a meeting of experts in Vienna, Austria, on 12 and 13 March ended in discord. Supporters of the European site insisted that the meeting should publish a technical comparison of the two sites - which they claim would have shown up their strengths.

Supporters of the Japanese site, including the United States, countered that the technical discussions were meant to feed into a wider political decision on a site.

The outcome of the meeting - privately described as 'fiery' by participants - was a bland statement that it had agreed to disagree. No further meetings have been scheduled to decide on a site, and plans to consider making the experimental reactor part of a broader, international fusion-research package remain just plans.

One Japanese government official put a brave face on the situation. "We're going up the stairs one step at a time," he says. “There's no such thing as an endless staircase, so eventually we'll get there." A European fusion scientist close to the talks disagreed: "We're not going anywhere."

US sources familiar with the negotiations say that the government there wants to take a backseat, in the hope that Europe and Japan can come to an agreement. But many researchers wonder if an accord can be reached. "People in the United States have no idea how this will get resolved," says Stephen Dean, head of Fusion Power Associates, a Washington-based advocacy group for fusion research.

Others worry that a decision on location will not be reached by the summer, when US researchers are set to re-evaluate the nation's role in the project. "Europe and Japan have to arrive at a decision, otherwise this could go on forever," says Dale Meade, a physicist at the Princeton Plasma Physics Laboratory in New Jersey.

An eight-person European Union delegation went to Tokyo this week to seek agreement with Japanese experts and government officials. One European scientist privately branded the trip "mission impossible".

But despite the deadlock, India last week became the latest nation to say it might join the project. According to science secretary Valangiman Ramamurthy, it accepted an offer from David King, science adviser to Prime Minister Tony Blair, to join ITER as a partner of Britain, which will cost India less than joining the project as a full partner.

Additional reporting by Geoff Brumfiel, David Cyranoski and K. S. Jayaraman.

\section{Ice machine sheds light on climate history written in dust}

Jim Giles, Montreal

Astrophysicists working on an Antarctic particle-physics experiment have serendipitously created a device that can track ancient climate trends.

The researchers say that initial results from the probe, to be published in the next few weeks, could provide the most accurate record yet of global temperature change over the past million years. Climatologists think that average global temperature is closely correlated with levels of volcanic dust in the atmosphere - something they can track by careful examination of the polar ice caps.

The 'Dust Logger' arose from work in the 1980s by researchers interested in using polar ice in detecting subatomic particles called neutrinos. These stream in from space and occasionally collide with protons or neutrons in Earth, creating a shower of secondary particles. Researchers can identify the path of neutrinos by tracking light emitted when the new particles are formed.

The Antarctic Muon and Neutrino Detector Array (AMANDA) used this technique to spot its first neutrino in 2001. But to calibrate the detector, Buford Price, an astrophysicist at the University of California, Berkeley, had to read up on how the movement of light through ice is affected by dust trapped within it.

Price, together with his graduate student Ryan Bay, soon realized that they could generate data on dust levels in the ancient atmosphere by measuring the optical properties of ice below the Antarctic surface.

The first tests of the Dust Logger took place in 2001, using holes drilled to extract cores of ice for other palaeoclimate experiments. The logger sends out bursts of light that last a nanosecond, and by recording how long it takes for the light to be reflected back to the logger, Price and Bay can estimate the dust content at different depths.

The results were discussed at the March meeting of the American Physical Society in Montreal, Canada, and are due to appear in the Proceedings of the National Academy of Sciences. They track levels in an Antarctic bore hole 1 kilometre deep, which is the equivalent to looking back on about a million years of climate history. The logger revealed 60-70 peaks in dust levels thought to be caused by volcanic eruptions. Less than 20 such peaks had been identified from direct examination of the ice core, says Price. 